\title{
ESPR uroradiology task force imaging recommendations in paediatric uroradiology, part VII: standardised terminology, impact of existing recommendations, and update on contrast-enhanced ultrasound of the paediatric urogenital tract
}

\author{
Michael Riccabona • Pierr-Hughes Vivier • Akaterina Ntoulia • Kassa Darge • Fred Avni • \\ Frederika Papadopoulou • Beatrice Damasio • Lil-Sophie Ording-Muller • \\ Johan Blickman • Maria-Luisa Lobo • Ulrich Willi
}

Received: 3 March 2014 / Revised: 15 July 2014 / Accepted: 16 July 2014

(C) Springer-Verlag Berlin Heidelberg 2014

\begin{abstract}
Our purpose is to harmonise and standardise terminology in paediatric uroradiology, to provide and update recommendations for contrast-enhanced US to standardise imaging and encourage further research, and to assess the impact of the existing recommendations in paediatric urogenital imaging. Based on thorough review of literature and variable practice at several centres and after discussion within urogenital imaging groups as well as with other subspecialties, we propose a standardisation of terminology in urogenital imaging. An update with recommendations on paediatric contrast-enhanced US has been issued based on available literature and reports. Finally, a
\end{abstract}

\section{Riccabona $(\triangle)$}

Department of Radiology, Division of Pediatric Radiology,

University Hospital LKH Graz,

Auenbruggerplatz 34, A-8036 Graz, Austria

e-mail: michael.riccabona@klinikum-graz.at

P.-H. Vivier

Department of Radiology, Hôpital Privé de l'Estuaire,

Le Havre, France

A. Ntoulia

Department of Radiology, The Children's Hospital of Philadelphia, Philadelphia, PA, USA

\section{K. Darge}

Department of Radiology, The Children's Hospital of Philadelphia,

University of Pennsylvania, Philadelphia, PA, USA

F. Avni

Department of Pediatric Radiology, Jeanne de Flandre Hospital Lille, Cedex, Lille, France

F. Papadopoulou

Pediatric Ultrasound Center, Thessaloniki, Greece questionnaire has been used to assess the knowledge, applicability and usefulness of, and the adherence to existing recommendations of the European Society of Paediatric Radiology (ESPR) Uroradiology Task Force. In conclusion, the ESPR is working to improve patient safety and optimise paediatric urogenital imaging. Standardisation of terminology and provision of updated knowledge on contrast-enhanced US in childhood will contribute to this task, ideally reducing the need for invasive or radiating imaging. Not all existing recommendations are commonly known, which limits adherence to these recommendations and the availability of comparable data and

B. Damasio

Department of Radiology, G. Gaslini Institute, Genoa, Italy

L.-S. Ording-Muller

Department of Radiology and Nuclear Medicine,

Unit for Paediatric Radiology, Oslo University Hospital,

Oslo, Norway

J. Blickman

Department of Radiology,

University of Rochester School of Medicine,

Rochester, NY, USA

M.-L. Lobo

Department of Radiology, Hospital de Santa Maria-CHLN, Lisbon, Portugal

U. Willi

Department of Radiology, Johns Hopkins University,

Baltimore, MD, USA 
evidence for future adaptation of imaging strategies in paediatric uroradiology.

Keywords Uroradiology · Child · Terminology · Standardisation · Contrast-enhanced ultrasound . Contrast-enhanced voiding urosonography $\cdot$ Imaging recommendations $\cdot$ Procedural recommendations

\section{Introduction}

The European Society of Paediatric Radiology (ESPR) Uroradiology Task Force has worked diligently in creating multiple imaging and procedural recommendations addressing a large variety of common queries in paediatric urogenital radiology.

The objective of this work in cooperation with the European Society of Urogenital Radiology Paediatric Working Group is to standardise imaging and to prevent unnecessary radiation and potentially invasive investigations without losing diagnostic reliability, not only in terms of improving diagnostic imaging but also to create a common platform to allow more evidence from future research to update existing recommendations. All these recommendations are in the form of openaccess articles freely accessible on the Internet.

The presented projects include (1) an effort to harmonise and standardise terminology in paediatric uroradiology, to avoid potentially misleading and unsafe perceptions and communications, (2) to update information on contrast-enhanced US in the paediatric genitourinary tract and (3) to try to assess whether all these efforts have an impact on daily imaging on a larger scale.

\section{Standardizing terminology in paediatric uroradiology}

In practice, one might commonly observe that general practice clinicians are not familiar with some common paediatric uroradiology terms. Additionally, radiologists, urologists and nephrologists do not always use the same terms with exactly the same meaning. An example is hydronephrosis, which is basically only a descriptive term. However, it is sometimes misunderstood as an implication of pathology, thus wrongly indicating further imaging or treatment.

To avoid potential misunderstandings the group proposed to clarify some of the most common and important terms. The aim was not to redefine existing terms but to standardise them — partially relying on pathophysiological mechanisms and partially just defining terms by referring to existing definitions based on terminology articles or collaborative works. The goal of this work is to provide a catalogue of commonly used terms in paediatric uroradiology that can be accepted by all physicians involved with management of paediatric nephrourological disorders, helping to avoid potentially misleading terms (Table 1).
In general, simple descriptive terms are recommended and the use of complicated or ambiguous ones is discouraged. In the effort to establish wide acceptance, this work was collaborative - the terms were reviewed by the members of the ESPR Uroradiology Task Force and the European Society of Urogenital Radiology Paediatric Working Group, and essential issues were then discussed publicly during the uroradiology task force session in Budapest at the ESPR 2013 congress and in Istanbul at the European Society of Urogenital Radiology 2013 annual meeting (Table 2).

A few terms are not radiologic, such as those pertaining to lower urinary tract functional disorders, but also have to be known and understood by paediatric radiologists and thus will be included. The proposed glossary is being assessed by a panel of renowned European (paediatric) urologists and nephrologists. Their comments will then be integrated to provide for a better description of pathological disorders and better communication between (paediatric) radiologists, (paediatric) urologists and surgeons, and paediatricians or (paediatric) nephrologists. More information on the confusion of terms can be found in the literature listed in the end of this paper.

\section{Update on contrast-enhanced ultrasound}

Since the introduction of stable US contrast agents nearly two decades ago, they have been increasingly applied in examinations of the paediatric urogenital tract. Since the withdrawal of the first-generation US contrast agent Levovist ${ }^{\circledR}$ (Schering, Berlin, Germany) from the market, the US contrast agents used in children have included SonoVue ${ }^{\circledR}$ (Bracco, Milan, Italy), mostly in Europe and Asia, and Optison ${ }^{\circledR}$ (GE Healthcare, Milwaukee, WI) in the United States; but neither is registered for use in children. Thus all paediatric US contrast agent applications are off-label, requiring informed consent in some jurisdictions.

\section{Contrast-enhanced voiding urosonography}

The most common paediatric application of US contrast agents is contrast-enhanced voiding urosonography, i.e. the intravesical application of US contrast agents via a bladder catheter for the evaluation of vesico-ureteric reflux. The procedure and its diagnostic accuracy are well-established and documented. More recent data have confirmed the high safety of the investigation with SonoVue, with no reported side effects attributed to the contrast agent alone, in more than 5,000 applications. With better contrast visualisation techniques reflux detection has become more conspicuous and common. Even intrarenal reflux can be more clearly visualised. Several recent papers show that transperineal US during voiding allows for reliable assessment of urethral pathology. Thus one of the early restrictions for 
Table 1 Examples of proposed standardisation of terms: recommended terms, synonyms not recommended and comments for enhanced understanding, definition or explanation

\begin{tabular}{|c|c|c|}
\hline Correct terms & $\begin{array}{l}\text { Not recommended } \\
\text { synonyms }\end{array}$ & Comments \\
\hline Pole (upper/lower) & (Upper/Lower) moiety & $\begin{array}{l}\text { Pole describes the (upper/lower) part of a non-duplicated kidney. Not to be confused } \\
\text { with a moiety. }\end{array}$ \\
\hline Complete duplication & $\begin{array}{l}\text {-Ureteral duplication } \\
\text { - Duplicated ureter } \\
\text { - Duplex system } \\
\text { - Double kidney }\end{array}$ & Definition: renal unit with two ureters, each with a separate vesicoureteric junction \\
\hline Incomplete duplication & $\begin{array}{l}\text { - Ureteral bifidity } \\
\text { - Bifid ureter } \\
\text { - Duplex system } \\
\text { - Double kidney }\end{array}$ & Definition: renal unit with two ureters but a single shared vesicoureteric junction \\
\hline Moiety (upper/lower) & (Upper/lower) pole & The term moiety is used when there is incomplete or complete duplication \\
\hline $\begin{array}{l}\text { Ureterocele of the upper moiety } \\
\text { ureter }\end{array}$ & $\begin{array}{l}\text { - Fetal ureterocele } \\
\text { - Ectopic ureterocele }\end{array}$ & $\begin{array}{l}\text { This is ureterocele of the upper moiety ureter in the setting of complete ureteral } \\
\text { duplication }\end{array}$ \\
\hline Single-system ureterocele & $\begin{array}{l}\text { - Adult ureterocele } \\
\text { - Simple ureterocele }\end{array}$ & Ureterocele in the absence of complete duplication \\
\hline High-grade vesico-ureteric reflux & $\begin{array}{l}\text { - Secondary megaureter } \\
\text { - Refluxing megaureter }\end{array}$ & $\begin{array}{l}\text { High-grade vesico-ureteric reflux ( } \geq \mathrm{III}) \text { is defined by dilatation of the proximal renal } \\
\text { tracts }\end{array}$ \\
\hline Ureteral dilatation & $\begin{array}{l}\text { - Hydroureter } \\
\text { - Megaureter } \\
\text { - Ureterectasis }\end{array}$ & Dilatation often occurs without chronic obstruction \\
\hline Primary megaureter & Obstructive megaureter & Not necessarily associated with obstruction \\
\hline $\begin{array}{l}\text { Loss of corticomedullary } \\
\text { differentiation }\end{array}$ & Renal dysplasia & Dysplasia is a histological term \\
\hline
\end{tabular}

contrast-enhanced voiding urosonography has been overcome. Though no dose findings studies have been performed by the manufacturers of these US contrast agents, laboratory research has defined and suggested a dose for this application, which is $0.2-1.0 \%$ of the actual bladder filling for SonoVue ${ }^{\circledR}$ and $0.5 \%$ of the actual bladder filling volume for Optison ${ }^{\circledR}$. The newly updated flow chart of the ESPR and European Society of Urogenital Radiology procedural recommendation can be seen in Fig. 1.

\section{Intravenous contrast-enhanced urosonography}

There is far less experience with intravenous use of US contrast agents in children, particularly in paediatric renal examinations.
Most of the experiences with intravenous contrastenhanced US have been in liver applications, mostly for detection and classification of liver lesions, as well as in diagnosing infectious lesions, or in trauma for assessing parenchymal organ injury. Today more than 1,000 applications in children have been reported, which demonstrates that this technique is successful and reliable and may help to avoid, or at least to reduce the use of, CT. However, recently some side effects have been noted: in five children minor side effects have been observed; additionally, more recently, in two children severe side effects such as bronchospasm, dyspnoea and skin reactions were reported (German Pediatric Radiology Society meeting in September 2013, Jena, Germany), including in one occasion a severe allergic reaction with hypotension, bradycardia, skin reaction and
Table 2 Suggested standardisation of terminology: comparison of recommended terms and terms that are better avoided. These terms are solely descriptive; none of them implies that obstruction is present.
Hydronephrosis is grading by the adapted ESPR classification based on the Hofmann ultrasonography grading and the Society for Fetal Urology proposal

\begin{tabular}{lll}
\hline Definition & Recommended term & Terms to avoid \\
\hline Dilatation of calyces & Caliceal dilatation & Calicectasis, Caliectasis \\
Dilatation of calyces and renal pelvis & Pelvicaliceal dilatation, hydronephrosis & Pelvocaliectasis, Pyelocaliectasis \\
Dilatation of renal pelvis alone & Pelvic dilatation, hydronephrosis grade 1 & Pelviectasis, Pyelectasis \\
Dilatation of calyces, renal pelvis and ureter & Hydroureteronephrosis & Megaureter, Ureterectasis \\
Dilatation of ureter alone & Ureteral dilatation, Hydroureter & \\
\hline
\end{tabular}


Fig. 1 Updated procedural recommendation on contrastenhanced voiding urosonography based on the ESPR/European Society of Urogenital Radiology 2008 recommendation implementing new developments, including a general list of accepted/suggested indications

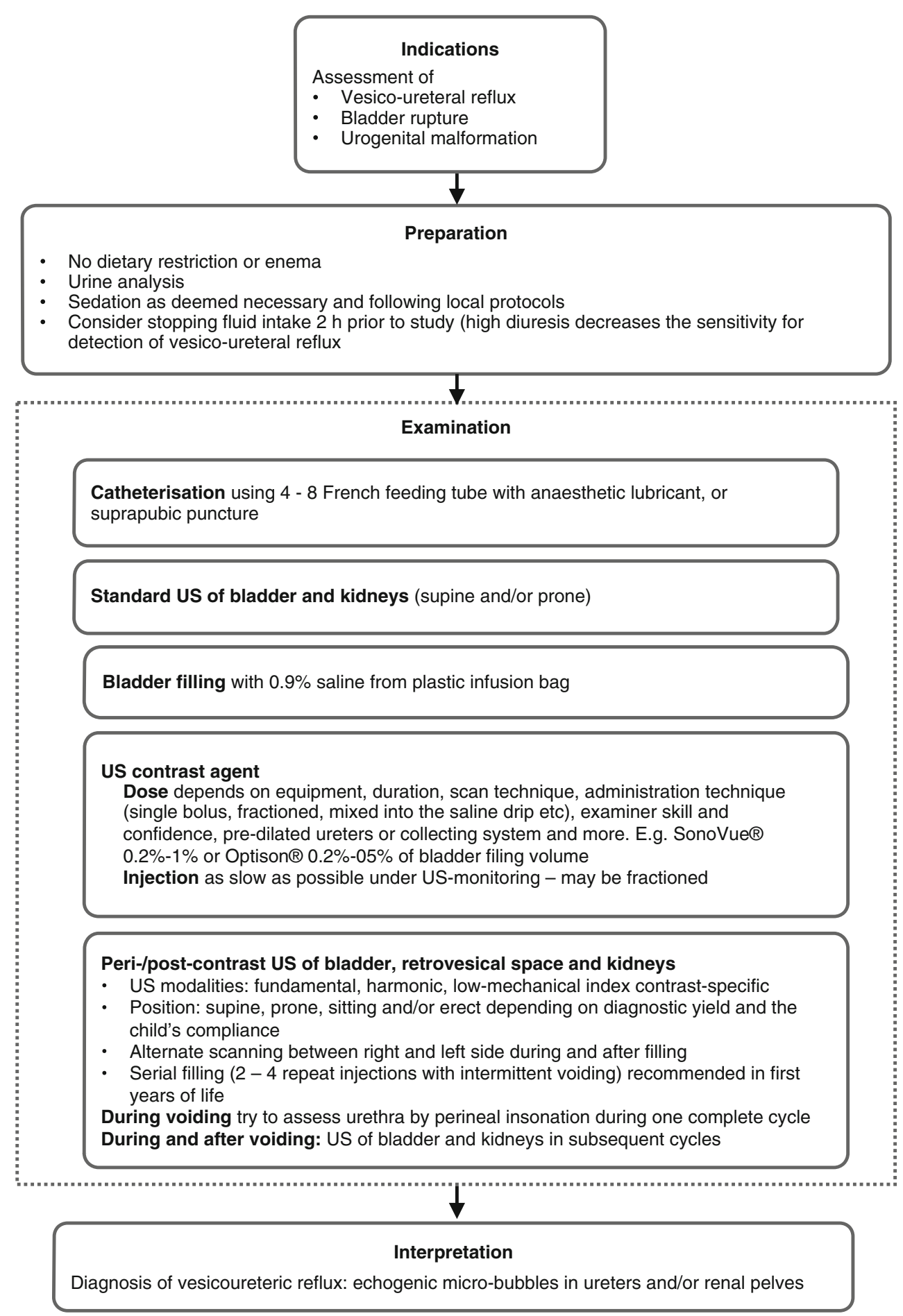

dyspnoea necessitating oxygen supply and adrenalin administration with intensive care surveillance for several hours. Thus, the pros and cons of intravenous contrast-enhanced urosonography have to be carefully considered, taking the benefit of potential reduction of contrast-enhanced CT (also with the need for intravenous administration of contrast agents) into account. A proper justification must exist, and proper precautions for monitoring and handling potential adverse reactions have to be taken. Based on the current knowledge and experiences with paediatric intravenous contrast-enhanced urosonography, a procedural recommendation on how and when to perform it in children has been proposed (Fig. 2). This also includes dose suggestions based on literature reports and personal experiences (extrapolating from the adult dose to paediatric weight and relative circulating blood volume, because no dose finding studies for children are available). 
Fig. 2 Procedural recommendation for intravenous contrast-enhanced US of the kidneys in childhood describes the proposal on how to perform renal intravenous contrastenhanced US in children, with dose suggestions and general potential indications

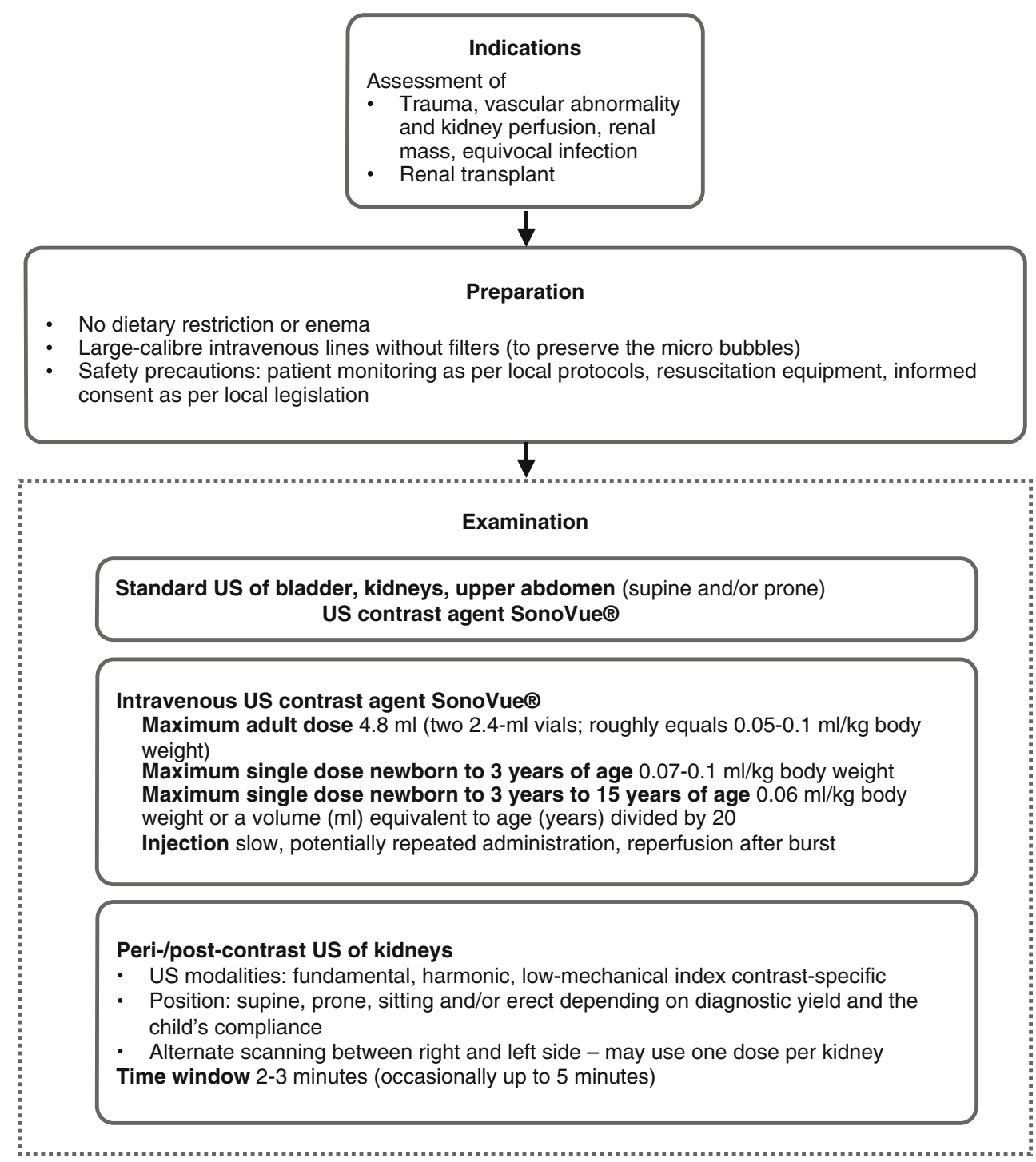

\section{Impact of procedural recommendations in paediatric urogenital radiology}

To assess the impact and appreciation of the ongoing work of the task force a questionnaire was distributed by email to 700 members of ESPR and the Society for German Speaking Paediatric Radiologists. The questionnaire asked to subjectively report on knowledge, adherence, adequacy and impact of the existing recommendations of the ESPR Uroradiology Task force and European Society of Urogenital Radiology Paediatric Working Group. Respondents were requested to tell us whether these were useful or potentially in need of an update. Further, the questionnaire tried to evaluate which of the professional groups endorses the recommendations: paediatric radiologists, general radiologists or clinicians.

The survey was conducted from October 2012 to March 2013. Responses where received, most of them using SurveyMonkey, an Internet-based online survey tool and software (SurveyMonkey, Portland, OR; http://www. surveymonkey.com). It yielded a response rate of only $9 \%$, not sufficient for definite conclusions. The answers generally came from throughout Europe, including Eastern Europe, but also a few from the United States, Canada and other countries. Forty-four members reported that they knew the recommendations from meetings, 15 from the literature and 26 from the Internet. Personal communications or visits to various departments were reported to have helped to spread the recommendations.

Responses are illustrated in Fig. 3. Not surprisingly the awareness of the existing recommendations was highest among paediatric radiologists who at least partially knew them (68/74; 92\%); only 6/74 (8.1\%) did not know them at all. It was a bit different for general radiologists — although the majority knew them at least partially $(53 / 61 ; 87 \%)$. Clinicians hardly knew any of them, only $42 / 73(58 \%)$ at least some nearly half of them $(31 / 73 ; 42 \%)$ were not aware of the 
Fig. 3 Impact of ESPR/European Society of Urogenital Radiology recommendations in paediatric uroradiology - responses to a questionnaire. Graphic shows the distribution of answers of the three groups to the four questioned items in percentages. Details are discussed in the text. Awareness Are the recommendations known? Adherence Are the recommendations followed? Impact Did these change your clinical and everyday practice? Adequacy Are the recommendations useful or helpful, and/or did they change the disease understanding or approach?

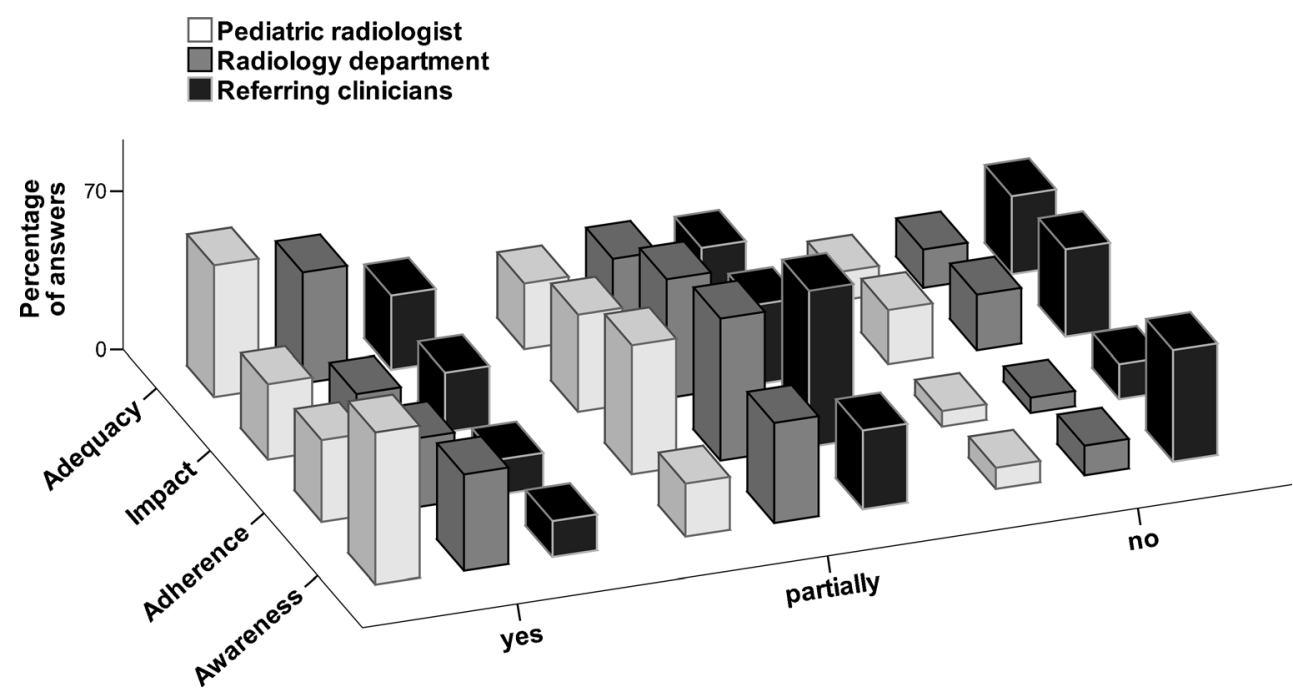

existence of these recommendations. The majority of respondents in all three professional groups only partially adhere to these recommendations, and furthermore the recommendations were thought to have only partially impacted and changed clinical everyday practice. The lowest impact was seen in the group of clinicians. The highest impact was noted among paediatric radiologists: $48 / 63(76 \%)$ at least partially recognised an impact of the recommendations on their everyday practice. The most commonly cited recommendations that had an impact were the various procedural guidelines and the imaging recommendations for childhood urinary tract infection as well as postnatal assessment of antenatally diagnosed hydronephrosis. Despite these observations, a relatively high number of paediatric and general radiologists as well as clinicians stated that the recommendations were at least partially helpful and changed their understanding of disease and the imaging modalities, particularly the guidelines on contrastenhanced voiding urosonography, voiding cystourethrography, urinary tract infection, hydronephrosis and obstructive uropathy, and childhood hypertension. Only a small group requested an update or revision in a few, often controversial topics, such as imaging of urinary tract infection and neonatal hydronephrosis workup - partially because of conflicts with local or national recommendations. A more common remark was the wish to simplify the recommendations, which is very difficult practically, given the complexity and need for applicability to different systems, local guidelines and individual demands.

\section{Summary}

A list of clarified terms used in paediatric uroradiology has been provided and discussed. This work is ongoing and requires feedback from and agreement among the specialties involved: (paediatric) radiologists, (paediatric) urologists and surgeons, paediatricians and (paediatric) nephrologists.

Contrast-enhanced US is still (and probably will be for the next few years) an off-label investigation throughout childhood. However, many applications have been reported. Their use and application as well as the respective research are now also promoted by the new International Contrast Ultrasound Society. Thus, growing attention needs to be paid to this development, reasonable recommendations have to be issued, probably more dose findings studies and analysis of defined patients cohort (e.g., using multi-centre patient registries, as presently promoted by the European Federation of Societies for Ultrasound in Medicine and Biology) have to be performed to properly understand and document the utility of intravenous contrast-enhanced US. This will allow further definition of its role in the armamentarium of imaging modalities applicable throughout infancy and childhood and in the consideration of first reports of some rare but nevertheless severe side effects like anaphylactic reactions that require adequate precautions for proper and professional handling of such events.

The existing 10 paediatric procedural recommendations and the 11 proposals for imaging algorithms in paediatric uroradiology are somewhat known to most paediatric radiologists, less to general radiologists, and the least to clinicians with concordant voting for the other aspects such as use and impact. This implies a need for better communication with general radiologists and even more with clinicians to increase awareness of existing recommendations and the rationale behind these approaches. Enhanced communication is also needed to discuss applicability, and - eventually — feedback to enable a respective update of recommendations based on or leading to a wider acceptance. Paediatric radiologists need to engage in creating clinical guidelines so that the paediatric radiology recommendations impact those guidelines that are most commonly used by clinicians. 
Finally, because all these aspects are a work in progress, we invite all readers' comments and suggestions on these and earlier recommendations in order to improve these recommendations and thus contribute to the task force work.

\section{Conflicts of interest None}

\section{References}

\section{Standardisation of terminology}

1. Fernbach SK, Maizels M, Conway JJ (1993) Ultrasound grading of hydronephrosis: introduction to the system used by the Society for Fetal Urology. Pediatr Radiol 23:478-480

2. Feldkamp ML, Botto LD, Amar E et al (2011) Cloacal exstrophy: an epidemiologic study from the international clearinghouse for birth defects surveillance and research. Am J Med Genet C: Semin Med Genet 157C:333-343

3. Fotter R, Riccabona M (2005) Functional disorders of the lower urinary tract in children. Radiologe 45:1085-1091

4. Glassberg KI, Braren V, Duckett JW et al (1984) Suggested terminology for duplex systems, ectopic ureters and ureteroceles. J Urol 132:1153-1154

5. Hjalmas K (1976) Micturition in infants and children with normal lower urinary tract. a urodynamic study. Scand J Urol Nephrol Suppl 37:1-106

6. Jansson UB, Hanson M, Hanson E et al (2000) Voiding pattern in healthy children 0 to 3 years old: a longitudinal study. J Urol 164: 2050-2054

7. Koff SA (1983) Estimating bladder capacity in children. Urology 21:248

8. Koff SA (1987) Problematic ureteropelvic junction obstruction. J Urol 138:390

9. Neveus T, von Gontard A, Hoebeke P et al. (2006) The standardization of terminology of lower urinary tract function in children and adolescents: report from the Standardisation Committee of the International Children's Continence Society. J Urol 176:314-324

10. Nguyen HT, Herndon CD, Cooper C et al (2010) The Society for Fetal Urology consensus statement on the evaluation and management of antenatal hydronephrosis. J Pediatr Urol 6:212-231

11. Peters CA (1995) Urinary tract obstruction in children. J Urol 154: 1874-1883, discussion 1883-1874

12. Riccabona M, Avni FE, Blickman JG et al (2008) Imaging recommendations in paediatric uroradiology: minutes of the ESPR workgroup session on urinary tract infection, fetal hydronephrosis, urinary tract ultrasonography and voiding cystourethrography, Barcelona, Spain, June 2007. Pediatr Radiol 38:138-145

13. Riccabona M (2012) Functional disorders of the lower urinary tract in childhood: an update. Pediatr Radiol 42:S433-S434

Update on contrast-enhanced ultrasound in childhood

14. Darge K, Papadopoulou F, Ntoulia A et al (2013) Safety of contrastenhanced ultrasound in children for non-cardiac applications: a review by the Society for Pediatric Radiology (SPR) and the International Contrast Ultrasound Society (ICUS). Pediatr Radiol 43:1063-1073

15. Duran C, Valera A, Alguersuari A et al (2009) Voiding urosonography: the study of the urethra is no longer a limitation of the technique. Pediatr Radiol 39:124-131

16. Duran C, del Riego J, Riera L et al (2012) Voiding urosonography including urethrosonography: high-quality examinations with an optimised procedure using a second-generation US contrast agent. Pediatr Radiol 42:660-667

17. Papadopoulou F, Ntoulia A, Siomou E et al. (2011) Safety of intravesical use of a second generation US contrast agent in children for vesicoureteric reflux detection. ECR Book of Abstracts, Insights Imaging 3: Suppl 1 (SS 1612), B-736

18. Robrecht J, Darge K (2007) In vitro comparison of a $1^{\text {st }}$ - and a $2^{\text {nd }}$ generation US contrast agent for reflux diagnosis. Fortschr Röntgenstrahlen 179:818-825

19. McCarville MB, Kaste SC, Hoffer FA et al (2012) Contrast-enhanced sonography of malignant pediatric abdominal and pelvic solid tumors: preliminary safety and feasibility data. Pediatr Radiol 42:824 833

20. Riccabona M (2012) Application of a second-generation US contrast agent in infants and children - a European questionnaire-based survey. Pediatr Radiol 42:1471-1480

21. Batko T, Kosiak W, Piskunowicz M et al (2013) Contrast-enhanced US in assessment of solid tumors vasculature in children - one center experience. Ultraschall Med 34:S31-S32

22. Piskunowicz M, Kosiak W, Batko T (2012) Intravenous application of second-generation ultrasound contrast agents in children: a review of the literature. Ultraschall Med 33:135-140

23. Piskunowicz M, Kosiak W, Batko T et al (2013) 'To be or not to be': intravenous application of second generation US contrast agents in children - safety considerations. Ultraschall Med 34:S32

24. Riccabona M (2014) Pediatric use of contrast media: safety issues. In: Thomson HS, Webb AW (eds) Contrast media: safety issues and ESUR guidelines, 3rd edn. Springer, Heidelberg New York Dordrecht London, pp 245-256

25. Kopac M, Riccabona M, Haim M (2009) Contrast-enhanced voiding urosonography and genitography in a baby with ambiguous genitalia and urogenital sinus. Ultraschall Med 30:299-300

\section{Recommendations in paediatric uroradiology}

26. Riccabona M, Avni FE, Blickman JG et al (2009) Imaging recommendations in paediatric uroradiology, part II: urolithiasis and haematuria in children, paediatric obstructive uropathy, and postnatal workup of foetally diagnosed high-grade hydronephrosis. Minutes of a mini-symposium at the ESPR annual meeting, Edinburg, June 2008. Pediatr Radiol 39:891-898

27. Riccabona M, Avni FE, Dacher JN et al (2010) ESPR Uroradiology Task Force and ESUR Paediatric Working Group: imaging and procedural recommendations in paediatric uroradiology, part III. Minutes of the ESPR Uroradiology Task Force mini-symposium on intravenous urography, uro-CT and MR-urography in childhood. Pediatr Radiol 40:1315-1320

28. Riccabona M, Avni F, Dacher JN et al (2011) ESPR Uroradiology Task Force and ESUR Paediatric Working Group: imaging recommendations in paediatric uroradiology, part IV. Minutes of the ESPR Uroradiology Task Force mini-symposium on imaging in childhood renal hypertension and imaging of renal trauma in children. Pediatr Radiol 41:939-944

29. Riccabona M, Avni F, Damasio B et al (2012) ESPR Uroradiology Task Force and ESUR Paediatric Working Group - imaging recommendations in paediatric uroradiology, part V: childhood cystic kidney disease, childhood renal transplantation, and contrast-enhanced ultrasound in children. Pediatr Radiol 42:1275-1283

30. Riccabona M, Lobo ML, Willi U et al (2014) ESPR Uroradiology Task Force and ESUR Paediatric Working Group - imaging recommendations in paediatric uroradiology, part VI: childhood renal biopsy and imaging of the neonatal and infant genital tract. Minutes from the task force session at the annual ESPR meeting 2012 in Athens on childhood renal biopsy and imaging neonatal genitalia. Pediatr Radiol 44:496-502 